Cell Physiol Biochem 1993;3:1

\title{
A Tribute to Peter Deetjen
}

\begin{tabular}{|l|l|l|}
\hline R. & Rainer & Greger \\
\hline F. & Florian & Lang \\
\hline S. & Stefan & Silbernagl \\
\hline
\end{tabular}

This issue of Cellular Physiology and Biochemistry is dedicated to Prof. Peter Deetjen.

Several of his scholars have decided to report here their most recent scientific findings in order to express their gratitude to their teacher and to celebrate his 60th birthday.

After having passed the usual peer review, the papers published here were selected for this honorary issue. 